\title{
Vélez de Guevara, Luis, Más pesa el rey que la sangre, y blasón de los Guzmanes, ed. William R. Manson y C. George Peale, est. introductorio Javier J. González Martí- nez, Newark, DE, Juan de la Cuesta, 2011, 162 pp. ISBN: 978-1-58871-211-0
}

\section{Ana Menéndez-Collera}

Suffolk County Community College ESTADOS UNIDOS

menendam@sunysuffolk.edu

[Hipogrifo, (issn: 2328-1308), 2.1, 2014, pp. 173-176]

Recibido: 21-11-2013 / Aceptado: 20-12-2013

DOI: http://dx.doi.org/10.13035/H.2014.02.01.14

El teatro español del siglo XVII constituye sin lugar a dudas uno de los fenómenos culturales y sociológicos más importante de nuestra historia literaria. Durante un poco más de cien años se escribieron más de 8000 comedias de muy diversos autores y géneros desde las comedias de privanza hasta las burlescas. Desgraciadamente muchas de estas obras y autores están faltos de ediciones fiables que permitan a los especialistas y lectores interesados leerlas con una mínima certeza de poseer un texto cercano a la voluntad del escritor. Afortunadamente en los últimos años asistimos a un gran aumento de ediciones de, al menos, nuestros dramaturgos más relevantes: Lope de Vega, Tirso de Molina, Mira de Amescua, Rojas Zorrilla o Calderón están siendo editados por especialistas que producen magníficas ediciones textuales de sus comedias. A estos hay que añadir a Luis Vélez de Guevara, de quien hemos perdido mucho de su corpus dramático, pero que está siendo ejemplarmente editado por William Manson y C. George Peale en la meritoria y prestigiosa editorial Juan de la Cuesta.

Del texto del que nos ocupamos en esta reseña, Más pesa el rey que la sangre, y blasón de los Guzmanes, ya existía una edición de Antonio Díez Mediavilla en la editorial Akal', pero sin el estudio ecdótico y con una escasa anotación para explicar palabras o pasajes difíciles de entender para el lector no especializado en la literatura del siglo XVII. La edición de Manson y Peale con el estudio introductorio

1. Luis Vélez de Guevara, Más pesa el rey que la sangre y Reinar después de morir, ed. Antonio Díez Mediavilla, Madrid, Akal, 2002. 
de Javier J. González Martínez viene, pues, a completar el conocimiento de un texto dramático interesante de nuestro teatro áureo.

El «estudio introductorio» se inicia con el analisis de la figura de Guzmán el Bueno y su presencia en la historia y la literatura españolas anteriores y contemporáneas a la obra de Vélez de Guevara. González Martínez analiza los dos textos históricos en los que pudo basarse nuestro dramaturgo: Ilustraciones de la Casa de Niebla de Barrantes Maldonado, finalizada en 1541, y La crónica de los duques de Medina Sidonia de Pedro de Medina, escrita en 1561. El estudioso piensa que el texto de Barrantes pudo ser la fuente en la que se basó Vélez para la escritura de su obra, de él sacó el episodio de la gran serpiente en Marruecos.

A continuación se describe sumariamente el argumento de la obra para centrarse en las cuestiones más importantes que atañen a la escritura y temática de la comedia. González Martínez piensa que la obra fue escrita probablemente en 1621, mientras el dramaturgo se hallaba al servicio de don Juan Téllez Girón, marqués de Peñafiel, primogénito del duque de Osuna. El editor basa su hipótesis en que «la interpretación que pueda tener una obra dramática histórica está intrínsicamente relacionada con el momento de escritura» (p. 17). De este dato deduce que se debe interpretar la obra como «la defensa del duque de Osuna» (p. 19) para lo que Vélez de Guevara apela en este texto a la genealogía de la familia del conde-duque . Esta opinión no concuerda con la de la ilustre tirsista Ruth L. Kennedy para quien la obra era una alabanza a los Guzmanes para conseguir la protección del conde-duque de Olivares. En cualquiera de los casos, nos encontramos con una comedia en la que se alaba a la nobleza, una característica importante de gran parte de su producción dramática, tal y como recuerda Ignacio Arellano que destaca «la constante vinculación de Vélez a la nobleza, que sí tiene reflejos en el tratamiento y selección de asuntos igualmente vinculados a esa aristocracia a la que sirve», por ello sitúa esta comedia entre aquellas cuya función es la de elogiar a la nobleza². González Martínez encuentra referecias en la obra de Vélez que relaciona con personajes o hechos de la vida del duque de Osuna, relacionadas sobre todo con su estancia como virrey de Nápoles. Así cree que el personaje de Jafer alude a laffier, personaje invoulcrado en la famosa Conjuración de Venecia (1618), de la que se acusó a Osuna como instigador, aunque hay historiadores que afirman que fue una treta de los venecianos para librarse de Osuna; también piensa que el cuchillo que Guzmán entrega al Infante para que mate a Pedro es reminiscencia del cuchillo regalado al duque por un emir. Para este estudioso la obra es una denuncia «de los favores que el rey hace a los que aun no han demostrado su valía y el desprecio de los que llevan años sirviendo al reino» (p. 20). Por tanto, habría que interpretar la comedia desde la situación de los Téllez-Girón al principio del reinado de Felipe IV; momentos en los que que el duque de Osuna se halla encarcelado, acusado de traición a la Corona. También piensa que es histórica y relaciona la obra con la Historia: la intercesión de las dos esposas (Osuna y Guzmán) ante Felipe IV y Sancho IV, respectivamente.

2. Ignacio Arellano, Historia del teatro español del siglo XVII, Madrid, Cátedra, 1995, p. 311. 
Me parece interesante la teoría de González Martínez, pero las referencias a Osuna son más bien vagas y desde luego la referencia a la Conjuración de Venecia no le hacía ningún favor a Pedro Téllez de Girón, pues de haber sucedido tal suceso lo habría hecho sin la autorización de Madrid. Creo que la obra es un elogio de la casa de los Guzmanes a la que pertenecía el conde-duque de Olivares, el todopoderoso valido de Felipe IV, del que Vélez pretendía recibir protección.

El siguiente apartado del «estudio introductorio» se dedica al tema de la representación de la obra. El crítico piensa que, aunque la comedia es de ámbito cortesano, la comedia se estrenó en un corral de comedias. Pero, como muy bien recuerda, los dramaturgos escribían textos que podían ser representados en ambos lugares: corral de comedias o palacio o salón de la residencia de algún noble. González Martínez cita el hecho de que esta comedia se encontraba en posesión de compañías como la de Baltasar Pinedo y la de Tomás Fernández (p. 21n). Aunque también menciona el dato de que Damián Polo representó la obra en el Cuarto de la Reina el 4 de febrero de 1691, o antes. Destaca que aunque la representación de Más pesa el rey que la sangre no debió de ser espectacular «no faltó la original virtuosidad y la sorprendente apariencia característica de las puestas en escena de la obras de Vélez» (p. 22); así recuerda la aparición en escena de un león, una sierpe y otros elementos que contribuirían a la vistosidad de la representación.

Un breve apartado lo dedica a la presentación del protagonista Guzmán como un héroe, al que se identifica con el Cid, ambos «arquetípicos héroes de caballería» (p. 23). Estas semejanzas incluyen la caracterización de Guzmán como vasallo leal, la presencia de un rey injusto, el episodio en el cual el héroe domina a un león, y el hecho de que ambos personajes sufrieron un injusto destierro (p. 23). Ciertamente el elogio de la casa de los Guzmanes se agranda cuando se compara a Guzmán el Bueno con el Cid, el gran héroe castellano.

El último apartado lo dedica a la dramatización de los hechos históricos en la comedia. Nos encontramos con uno de los temas más interesantes en este tipo de obras: la adaptación de la historia al drama. González Martínez señala algunos de los cambios que introdujo Vélez en su obra frente a la Historia: cambio del nombre del infante Juan que Vélez convirtió en Enrique para identificarlo con el condeduque de Olivares, que enemistó a Felipe IV con los hombres de confianza de su padre. Otro aspecto que enfatiza es la importancia de la daga a lo largo de la obra, daga con la que el Rey amenaza al infante Enrique que defiende a Guzmán, que pasa a manos de Abén Jacob, que se la regala a Guzmán, que la entrega al Infante para que mate con ella a su hijo.

A continuación (pp. 29-48), Peale lleva a cabo el estudio textual de la comedia. El editor comenta la dificultad para rastrear la obra debido a que la comedia de Vélez «originó una larga y variada secuela... [porque] a veces los repertorios confunden títulos y autores» (p. 29). Los editores han cotejado las seis sueltas que se conservan con diferentes títulos y atribuciones distintas, aunque para su edición se han basado en S1, cuyo ejemplar se conserva en la Bibliothèque Nationale de Paris, y en el que curiosamente la obra se atribuye a Lope de Vega. Hay un minucioso análisis de las variantes que llega a un esclarecedor stemma con dos ramas: una en la que 
se halla S1 y otra a la que pertenecen los restantes testimonios. También presentan un interesante estudio de la versificación que les lleva a aceptar la propuesta de González Martínez de que la obra fue compuesta entre 1621 y 1622.

La edición del texto es muy cuidada. Los editores han decidido, como es habitual en este tipo de ediciones, modernizar la acentuación y la puntuación. El texto de la comedia está casi libre de erratas, solamente hemos encontrado la del verso 1717, donde leemos: «derechaa mano». Por lo que se refiere a la anotación es bastante completa, aunque echamos en falta alguna que otra nota, por ejemplo: «Cide» (v. 2097) y «perro» (v. 2177). Hemos de señalar un error en la nota del verso 169 «abadejo», que los editores afirman que es «mosca de España» (p. 139), definición que no aparece en Covarrubias que menciona un pescado, un ave y un «escarabajo ponzoñoso». También nos parece que sobra la definición de «jarabes» (v. 2053), que, según Peale, significa purgante en esta ocasión.

En conclusión, nos encontramos con una excelente edición de una interesante comedia de Luis Vélez de Guevara. El estudio introductorio sitúa la comedia en su momento histórico y analiza aspectos importantes como el elogio de la casa de los Guzmanes y el proceso de dramatización al que somete el dramaturgo la historia de Guzmán el Bueno. La edición del texto es muy cuidada y proporciona al lector la posibilidad de acercarse a una comedia que pertenece al tipo de los «elogios de nobles». No nos queda más que elogiar el proyecto de C. George Peale de editar el teatro de Luis Vélez de Guevara, con lo que se une a los editores de Lope de Vega, Tirso de Molina, Mira de Amescua, Rojas Zorrilla o Calderón en la ardua labor de dar a conocer las obras completas de nuestros mejores dramaturgos. 